\title{
THE U.K. ATOMIC ENERGY AUTHORITY
}

$\mathrm{T}$ HE tenth annual report of the Atomic Energy Authority* covers the year ended March 31, 1964, in which the Authority's staff was reduced by about 5 per cent because production of uranium-235 for military purposes at Capenhurst ceased and most of the capital works programme has been completed. Of the $£ 45$ million expended on civil research and development, £36 million was current expenditure and $£ 9$ million on capital facilities ; research, development and design contracts with industry, univorsities, etc., amounted to $£ 4,612,000$ compared with an estimated $\mathfrak{f} 4,223,000$ in $1964-65$; contributions towards International Atomic Energy Agency projects were $£ 2.48$ million and grants to the National Institute for Research in Nuclear Science $£ 8,998,000$, compared with an estimated. $£ 1.36$ million and $£ 9,648,000$, respectively, in $1964-65$. Of 2,830 engineers and scientists employed at March 31, 1964,180 wore doing work for other organizations on repayment, 1,900 were engaged on the reactor development programme and reactor systems research, on which current expenditure is estimated at $£ 26$ million, 470 on general research ( $£ 6$ million), 200 on plasma physics and fusion research (£3 million), and 80 on isotopes research ( $£ 1$ million). Attention is directed to a reduction in the balance sheet of $\$ 50$ million in the value of work in progress, which is due mainly to the transfor of nearly $£ 30$ million to "loss on revaluation of fissile material", representing a writing-down of the value of material held for research purposes to bring the valuation in line with world prices. Uranium ore, no longer required for military purposes, other than supplies purchased for the nuclear power programme, will form a national stockpile in the custody of the Authority as agent for the Secretary of State for Education and Science, and the cost of the uranium in this stockpile will in future be excluded from the Authority's balance sheet. Of the $£ 52.5$ million received from the Authority's trading and other commercial activities during the year, $\mathfrak{£ 3 9 . 5}$ million was from sale of reactor fuel, fuel services, etc., $£ 7.9$ million from sales of electricity, $\mathfrak{L 1 \cdot 6}$ million from sales of isotopes and $£ 2.7$ million from sales of reactor-grade graphite.

On the production side development work on the gas centrifuge as an alternative to gaseous diffusion continued satisfactorily and productivity in the magnox fuel manufacturing process continued to increase, while the anticipated peak in production of magnox fuel at Springfields was reached. A separate chapter devoted to the reactor development programme estimates that at March $31,1964,19$ per cent of the scientists and engineers in the Reactor Research and Weapons Group were engaged in work on the advanced gas reactor, 17 per cent on the steam-generating heavy-water reactor system, which has the advantage of lower enrichment than the advanced gas reactor and the potentiality of producing superheated steam, 38 per cent on the fast reactor, 14 per cont on the civil marine reactor and 12 per cent on the high-temperature gas-cooled reactor for the Dragon project at Winfrith. In the advanced gas reactor encouraging progress is reported in protecting the graphite moderator from corrosion by the carbon dioxide coolant under irradiation and much information was also obtained on the dimensional changes in graphite caused by irradiation from irradiation experiments. The operational availability of the Windscale advanced gas reactor during its first year of power operation was 87 per cent and compares favourably with any other nuclear reactor built solely as a nuclear power station or otherwise. With fast reactors the out-

* United Kingdom Atomic Energy Authority. Tenth Annual Report for the period 1st April, 1963-31st March, 1964. Pp. ix + 89+8 plates. (London: H.M.S.O., 1964.) 68. 6d. net. standing achievement was to get the Dounreay fast reactor operating at full power and to continue at full power for the maximum time to build up irradiation experience of fast reactor fuels. General predictions of the kinetics of a high-power fast reactor have been shown to be substantially accurate and steps taken in design of the core to eliminate a positive power coefficient were successful. On marine reactors little is added to what was said in the Padmore Report (Nature, 202, 1248; 1964); work on the integral boiling reactor was mainly confined to physics of burnablo poison cores and to fuel element and core design investigations; work also continued on burnable poison cores and experimental physics studies were made of the characteristics of regular fuel element clusters, as well as investigations of the use of plutonium as a nuclear fuel for marine reactors.

A further chapter dealing with research on reactor systems records that, in the programme of nuclear measurements to provide data for calculating the physics characteristics of proposed reactors, the emphasis continues to be on measurements for fast reactors. A general investigation continued into the mechanism by which neutrons transfer their energy to liquids and solids and are thus brought into equilibrium with the atoms of a moderator, and a major advance in the established technique of transfer-function analysis for measuring the dynamic response of a nuclear power plant has been linked with the development of a neutron generating tube of high output capable of being modulated at frequencies up to $1,000 \mathrm{c} / \mathrm{s}$. Work on fuels has included studies of solid solutions of plutonium dioxide in uranium dioxide to determine the chemical (phase) stability under various conditions, and in work on carbide fuels reactor-grade material has been obtained by heating granules of fissile oxides with carbon in a stream of argon. Other work has been concerned with canning and structural materials, moderators and coolants and the design of biological shields for power reactors.

Among examples selected to illustrate the Authority's programme of general research in this report may be mentioned work which is directed at devising mathematical methods by which computers ean be used more efficiently and applied to a widor range of problems. In a programme of basic research on solid-state physics the emphasis is now moving to non-metallic solids such as oxides and carbides. The fundamental causes of changes in solids induced by radiation are also being investigated, while basic information bearing on steam-cooled systems is being sought in studies of the radiolysis of water-vapour, in which first results indicate that the net radiolytic decomposition of pure water is negligible, but with vapour containing ammonia or oxygen the primary decomposition is comparable with that of pure water. Other long-term research is concorned with the physical and chemical properties, and the fabrication behaviour, of the oxides, carbides, nitrides, sulphides and phosphides of fissile and fertile elements, especially the carbides. Some work also continues on fissile metals, and protactinium oxide has been investigated in detail for comparison with the oxide systems of the other actinide elements from thorium to plutonium. A major effort is devoted to improving existing methods of analysis and applying new ones, while an increase in the resolution with which chemists can measure the energies of $\alpha$-particles has led to a tenfold improvement in the sensitivity of certain measurements in health physics. The utility of $\gamma$-ray spectra for identifying the radionuclides present in various materials has been increased by the development of an automatic method of analysing complicated spectra and an absolute 
hygrometer has been developed for measuring the humidity of the stratosphere in investigations on fall-out.

In plasma physics and fusion research the main problems are still to identify, understand and control the many instabilities which prevent magnetic fields from confining extremely hot ions and electrons for more than a relatively brief moment. While these instabilities remain as a potential source of trouble in closed systems, there are now indications that they can be overcome in the open-ended magnetic traps. The programme also includes two experiments in 'Minimum $B$ ' geometry designed to see if the same freedom from interchange instabilities noted by Ioffe at the Kurchatov Institute will apply at higher plasma densities and with different methods of plasma injection. Besides investigations with a cusped field trap and a theatron trap, containmont with closed lines of force has been investigated and basic investigations made on plasma itself, particularly the propagation characteristics of the wide variety of wave motions which a magnotized plasma can support, and also the processes which can arise from collision between its constituent particles. At the Wantage Research Laboratory the feasibility of radioisotope $X$-ray fluorescence analysis for on-stream assay of zinc in zinc-lead ores has been investigated in co-operation with the Department of Scientific and Industrial Research, while invostigations bearing on health and safety have led to the development and manufacture of a personal neutron dosimeter. Studies of radioactivity in the human body continued using whole-body monitors and bioassay methods to determine the metabolic behaviour of nuclides, and continued physico-chemical study of chelating agents confirmed that diethylenetriamine pentacetic acid and triethylenetetramine hexacetic acid assist the removal of plutonium from the human body, but more effective and less toxic compounds are being sought.

The Reactor School programme at the Postgraduate Education Centre set up at Harwell on April 1, 1963, has been revised, and, after transfer of four of the more elementary courses, three new courses have been added: physics for engineers; language and technical writing; and a refresher course for senior technical executives. In collaboration with the European Nuclear Energy Agency a one-week residential course was given on health and safety aspects of radiation in industry for Trade Union officials. Of 379 students attending these courses, 340 were British and 39 from overseas, while 490 students attended a new series of postgraduate courses, and another 300 the 14 courses held in the Isotope School.

While the non-industrial staff fell over the year from 20,008 to 18,864 and industrial employees from 18,350 to 17,098 , the Authority made it clear to their staff that there is a large and continuing volume of work for the Authority, including civil research and development as well as production and processing. Some recruitment continued and the level will be raised in 1964, the need for young scientific and engineering graduates for research, design and development, and for training as future managers being mentioned, while 202 apprentices were recruited compared with 230 in the previous year.

The Authority has also published the tenth anniversary issue of Atom $\dagger$ including both an illustrated summary of the tenth annual report and an illustrated review of the developments during 1954-64.

† United Kingdom Atomic Energy Authority. Atom 1954/1964: an Atomic Energy Authority from April 1st, 1963, to March 31st, 1964. (Tenth Anniversary Issue.) Pp. 48. (London: H.M.S.O., 1964.) 28.6d.

\section{THE SOUTH AFRICAN ATOMIC ENERGY BOARD}

$\mathrm{T}$ HE South African Atomic Energy Board was set up in March 1949, and at first confined its operations almost exclusively to administrative procedures related to the mining, extraction and sale of uranium concentrates, the distribution and control of radioisotopes, mineral investigations, and the study of the production of heavy water. During 1957 detailed planning of an atomic energy resoarch and development programme for South Africa was started, and on September 5, 1959, the then Minister of Mines, Mr. J. de Klerk, announced the Government's acceptance of the proposed programme. This covered an initial period of five years. The Way to Pelindaba is an illustrated description of the main activities during that period $1959-64 *$.

The programme called for both electric power production by nuclear fission, and for radioisotope and radiation applications, and necessitated the provision of a nuclear reactor for research and a suitably located research centre. It was decided, in 1960 , to construct a $20-\mathrm{MW}$ high-flux light water moderated and cooled reactor of the Oak Ridge type, suitable for materials testing and for operation initially at about $5 \mathrm{MW}$. A contract for the supply of $S A F A R I$-1 (South $A$ frican Fundamental $A$ tomic Reactor Installation) was signed with the authoritios of the United States. A site, on a farm formerly known as Wilgegund, was chosen for the nuclear research centre, and named Pelindaba, from the Bantu pelila indaba, meaning 'the discussions are finished'. Construction commenced in July 1961, and two years later, in July 1963 , the administration building and part of the reactor building were occupied. The chemistry building, the Van de Graaff accelerator building, the water purification

* South African Atomic Energy Board. Brochure No. 1: The Way to Pelindaba. Pp. 28. Brochure No. 2: Pelindaba-National Nuclear Research Centre of the South African Atomic Energy Board. Pp. 31. (Pretoria: South African Atomic Energy Board, 1964.) works and a portion of the reactor engineering building were completed by the end of 1963. Unfortunately, accidental damage to the reactor vessel of $S A F^{\prime} A R I$ in the United States during test delayed its delivery to South Africa, but the repaired vessel eventually arrived on Christmas Day 1963 and by March 1964 it was installed, together with most of its heavy concrete shield, within the reactor building. The Van de Graaff acceleratora 3-MeV high-intensity beam typo-which provides a source of mono-energetic neutrons, with pulsing if required for the time-of-flight method, has also been erected and is now in commission. A detailed description of the site and layout of the nuclear research contre, together with diagrams of the site buildings, the accelerator and reactor, is given in the companion booklet Pelindaba (Brochure No. 2).

It is well known that South Africa contains some of the world's largest reserves of uranium and has been one of its largest producers. Indeed, until recently, 17 uranium extraction plants handling about 20 million tons of residue slimes from 26 mines, eight contact-process sulphuric acid plants, and a factory for the conversion of the custard-yellow cream emanating from the extraction plants were in continuous operation. All forms of refined uranium are produced in substantial quantities, the products including uranium metal, its carbide, trioxide and tetrafluoride, and small quantities of hexafluoride. A pilot plant has been constructed to investigate the production of a nuclear-grade uranium product, containing only a few parts per million of impurity, from the uranium extraction plants at the gold mines at Bufflesfontein. This is known as the Bufflex Project and was started in October 1963.

The research staff of the Atomic Energy Board, some eighty of whom have been trained or are still training at 